\title{
IMPROVEMENT OF MECHANICAL, THERMAL AND MORPHOSTRUCTURAL PROPERTIES OF SBS THERMOPLASTIC ELASTOMER USING KAOLIN AND DOLOMITE MICROPARTICLES WITH MODIFIED SURFACE
}

\author{
MARIA SÖNMEZ ${ }^{1}$, MIRCEA JUGANARU ${ }^{2}$, ANTON FICAI ${ }^{3}$, OVIDIU OPREA ${ }^{3}$, ROXANA \\ TRUȘCA ${ }^{3}$, MIHAI GEORGESCU ${ }^{1}$, DANA GURĂU ${ }^{1}$, DENISA FICAI ${ }^{3}$, LAURENȚIA \\ ALEXANDRESCU ${ }^{1}$, DOINA CONSTANTINESCU ${ }^{4}$, MARIA DANIELA STELESCU ${ }^{1}$, \\ MIHAELA NIȚUICA ${ }^{1}$, MINODORA MARIN ${ }^{1}$ \\ ${ }^{1}$ INCDTP - Division: Leather and Footwear Research Institute, 93 Ion Minulescu st., Bucharest, \\ Romania,maria.sonmez@icpi.ro \\ ${ }^{2}$ Protect Styl Industry S.R.L., 30 Bulevardul Unirii, 600192, Bacau, Romania, \\ mircea.juganaru@protectstyl.ro \\ ${ }^{3}$ Politehnica University of Bucharest, Faculty of Applied Chemistry and Material Science, 1-7 \\ Polizu St., Bucharest, Romania, anton.ficai@upb.ro \\ ${ }^{4}$ SC MONOFIL SRL, 5 F Gheorghe Caramfil str, Savinesti, Neamt, Romania, \\ monofil.srl@gmail.com
}

\begin{abstract}
The aim of this paper was to assess the influence of the modification of the surface of dolomite and kaolin with $\mathrm{SiO}_{2}$ and $\mathrm{TiO}_{2}$ precursors, on the block copolymer styrene-butadiene-styrene (SBS) type thermoplastic rubber properties. These composite materials were obtained by compounding SBS with various ratio of powders. Based on the SEM images it can conclude that the powders were homogenously dispersed in to the SBS matrix. The dolomite particles can be clearly identified in the SEM images as particles of 10 micrometers. The samples obtained with modified dolomite have similar morphology. The EDS elemental distribution confirming a good corroboration between the elements of the dolomite, kaolin and titanium or silicon elements. Based on the thermal analysis according to the residual mass, the presence of $20 \%$ mineral phase can be confirmed. According to the DSC curves a strong stabilization of the composite appears, because of the presence of the mineral component. According to the physical-mechanical data all the composite materials exhibit improved mechanical properties. Additionally, the modification of the kaolin and/or dolomite bring important improvements in mechanical properties. The samples 13 and 14 exhibit high tensile and tear strength. These composites can be used for various applications, such as, for instance, soles for firefighters' footwear.
\end{abstract}

Keywords: SBS thermoplastic rubber, interface, functionalization

\section{INTRODUCTION}

Styrene-butadiene block copolymers are an important class of synthetic rubber, composed of central rubber blocks and polystyrene ends. Hard styrene blocks induce mechanical and abrasion resistance, while butadiene improves flexibility and toughness. SBS rubber is widely used as an impact modifier in various plastics and adhesives, sealing materials, gaskets, rubber bands for wires and cables, shoe soles, toy parts and bitumenbased products for road paving and roofing applications, etc. (Jin et al., 2021). To improve performance (mechanical, thermal, etc.), styrene-butadiene-styrene (SBS) rubber is often compounded with other polymers (PP, PS, etc.) and/or other reinforcing agents $\left(\mathrm{TiO}_{2}\right.$, $\mathrm{SiO}_{2}$, carbon black, clay, talcum, graphene, $\mathrm{CaCO}_{3}, \mathrm{MgCO}_{3}$, multi-walled carbon nanotubes-MWCNTs, fullerene (C60), nanodiamond, etc.) (Bicy et al., 2018; Abdelsalam et al., 2019; Das et al., 2019; Sönmez et al., 2019; Costa et al., 2014; Perov, 2018). However, the interaction between the rubber matrix/filler is affected by several factors such as the chemical/physical interactions between the surface of the filler/polymer particles, the structure of the filler network, the shape, size, proportion of the filler, etc. 
(Abdelsalam et al., 2019). In the literature, there are no studies on the effect of dolomite and/or kaolin microparticles functionalized with $\mathrm{SiO}_{2}$ and $\mathrm{TiO}_{2}$ precursors on the physical-mechanical, morpho-structural and thermal properties of SBS rubber. Improving the properties of SBS rubber is of major importance in the industry, as it is used in a wide range of applications and by using low cost and high availability fillers, improved properties can be obtained.

\section{MATERIALS AND METODS}

\section{Materials}

The following raw materials were used for the processing of composites: Styrenebutadiene-styrene rubber (SBS) - type Eurruber from Tecnofil SME, Italy; Kaolin - calcined (Snowpaque), with particle size from 2 to $50 \mu \mathrm{m}$ and layer thickness from $13.2 \mathrm{~nm}$ to 19.25 $\mathrm{nm}$, purchased from Bridgexim SRL; DOLOFLOR dolomite powder, with the following composition: $\mathrm{CaO}-30-33 \%, \mathrm{MgO}-18-20 \%, \mathrm{pH}=9.67$, neutralization number $-59.55 \% \mathrm{CaO}$, particle size of several tens of $\mu \mathrm{m}$, manufacturer SC CEMROM SA.

\section{Method}

Composites based on SBS reinforced with $5 \mathrm{~g}$ kaolin powder and/or varying amounts (30-75g) of modified/unmodified dolomite relative to $100 \mathrm{~g}$ SBS were obtained according to Table 1 .

Table 1. Formulation based on SBS rubber reinforced with modified/unmodified particles, wt ratio

\begin{tabular}{|c|c|c|c|c|c|c|}
\hline Sample code / Raw materials & SBS & 11 & 12 & 13 & 14 & 15 \\
\hline SBS Rubber & 100 & 100 & 100 & 100 & 100 & 100 \\
\hline Kaolin & - & 5 & - & - & - & - \\
\hline Kaolin/10\%PDMS & - & - & 5 & - & - & - \\
\hline Kaolin/10\% $\mathrm{TiO}_{2}$ & - & - & - & 5 & - & - \\
\hline Dolomite & - & 30 & - & - & - & - \\
\hline Dolomite/5\%TEOS+5\% PDMS & - & - & 30 & - & - & 20 \\
\hline Dolomite $/ 5 \% \mathrm{TEOS}+5 \% \mathrm{TiO}_{2}$ & - & - & - & 30 & 20 & - \\
\hline Dolomite/ $10 \% \mathrm{TiO}_{2}$ & - & - & - & - & 55 & - \\
\hline Dolomite/10\%PDMS & - & - & - & - & - & 55 \\
\hline
\end{tabular}

The surface of kaolin and dolomite was modified by a methodology similar to the one described in the article published by Sönmez et al. (2019). Prior to the actual processing on the Brabender, the first step was assigned to drying the raw materials at $100^{\circ} \mathrm{C}$ in a hot air oven for several hours. The second stage consisted of processing the composites on a Brabender mixer, at $160^{\circ} \mathrm{C}$ and at different rotational speeds ( $30 \mathrm{rpm}, \sim 1$ minute, and at 130 $\mathrm{rpm}, \sim 3$ minutes). Depending on the amount of powder added (mixtures 14 and 15), the processing time increased by 2-3 minutes or until the total and uniform incorporation of the powders into the SBS mass took place. From the processed mixtures, plates with the size of 150x150x4 mm (length $\mathrm{x}$ width $\mathrm{x}$ thickness) were obtained in a metal mold, by the hot compression method. Press processing parameters: the temperature of the platters (upper and lower) was set at $170^{\circ} \mathrm{C}$, preheating and pressing time -4 minutes, cooling the platters -10 minutes. From the resulting composite plates, specimens with standardized dimensions 
and shapes were stamped (dumbbell specimen - tensile strength, elongation at break, modulus, and from the trouser-type specimen - tear strength was determined), in order to perform physical-mechanical tests. Following the physical-mechanical determinations, the tested specimens were used for thermal (DSC-TG) and morpho-structural analyses (SEM, EDS).

\section{RESULTS AND DISCUSSION}

\section{Energy Dispersive Spectroscopy (EDS) and SEM Analysis}
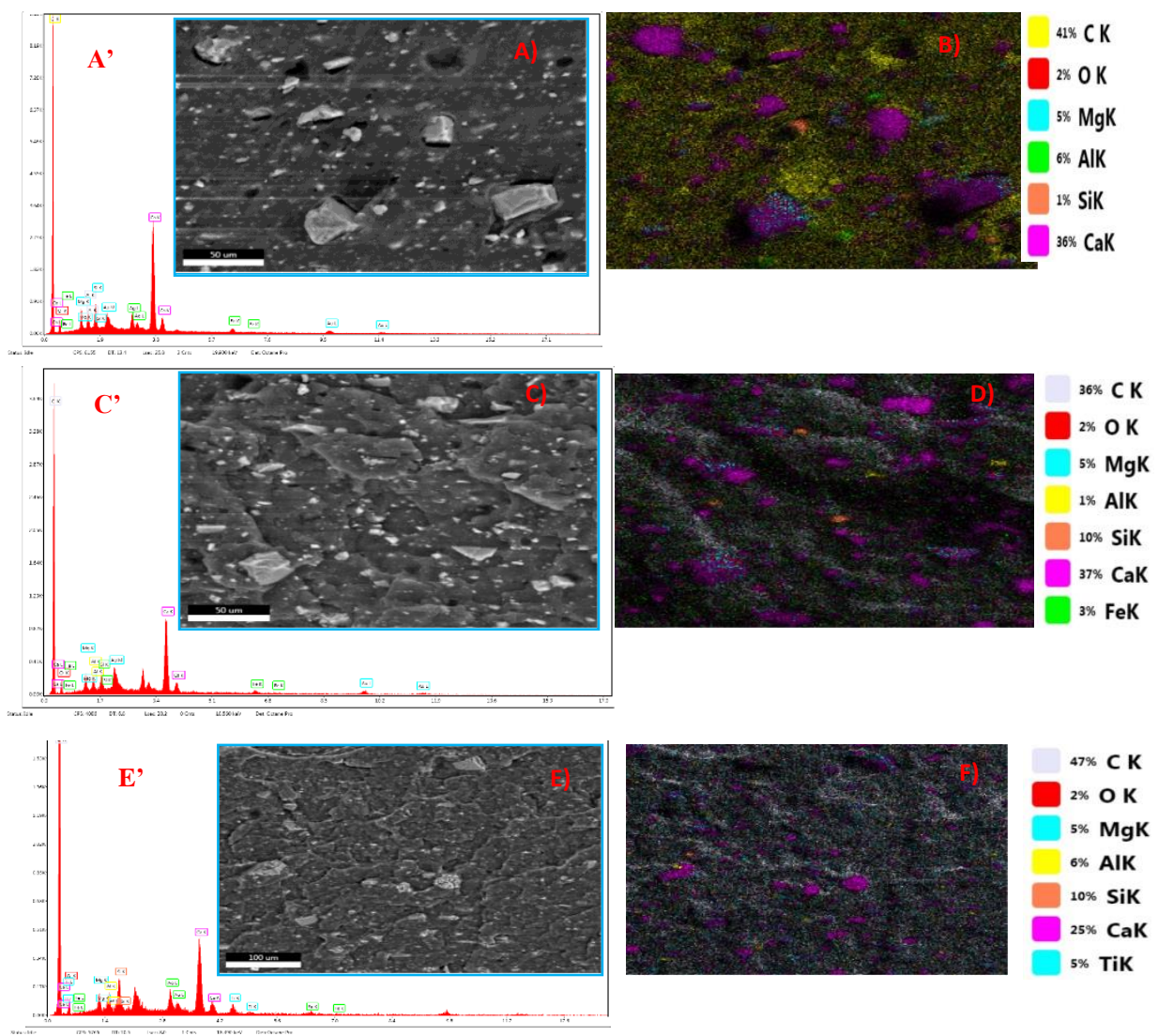

Figure 1. SEM image, EDS spectra and map of: Sample 11 (A, $\mathbf{A}^{\prime}$ and B); Sample 12 $\left(\mathbf{C}, \mathbf{C}^{\prime}\right.$ and D) and Sample 13 (E, E' and F)

Figure 1, image A for sample 11 in which the reinforcing agents are not chemically modified, kaolin and/or dolomite particles can be observed but also defects (of the order of tens of $\mu \mathrm{m}$ ) due to the detachment of the dispersed phase, which denotes a weak interaction between phases. In image $C$ of sample 12, due to surface modification, the large defects visible in sample 11 are not specific, probably due to a better matrix/ reinforcing agent interaction. In sample 13 the morphology changes considerably, the polyhedral reinforcing agent particles seem to be better embedded in the polymer matrix, 
and the rupture takes place mainly through the SBS matrix. The EDS elemental distribution (Figure 1, images B, D and F) confirming a good corroboration between the elements of the dolomite and titanium or silicon elements. The EDS spectra (images A', $\mathrm{C}^{\prime}$ and E') highlight the presence of component elements in dolomite (mainly $\mathrm{Ca}, \mathrm{Mg}$ ), kaolin (Al, Si, Fe) (Sönmez et al., 2019) and functionalizing agents (and additionally from PDMS, and/or silica from TEOS, Ti element).

\section{DSC-TG Thermal Analysis}

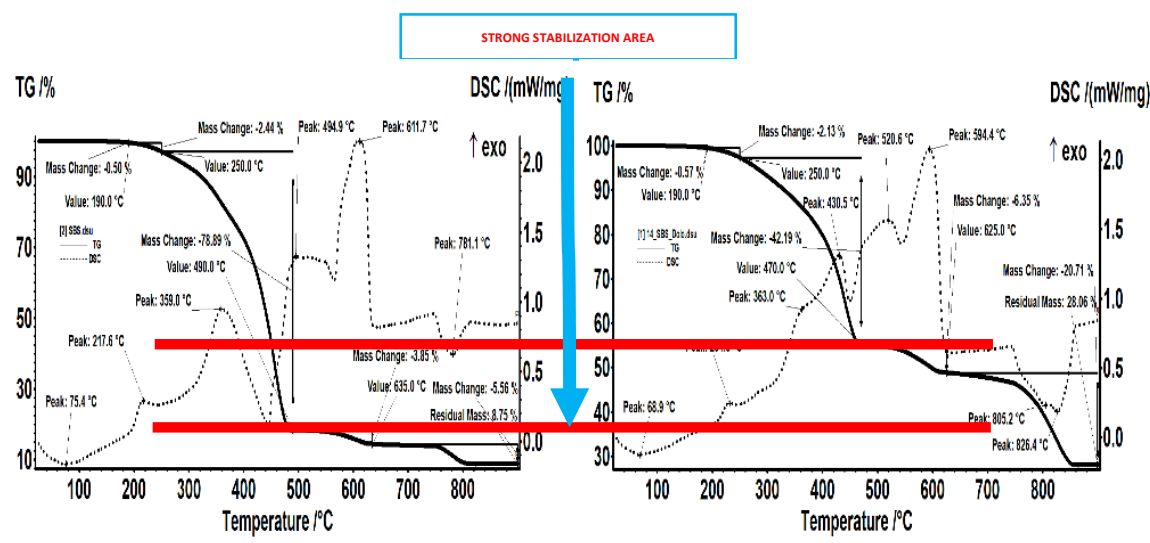

Figure 2. Thermal analysis of SBS rubber (left) and Sample 14 (right)

Thermal analysis performed on SBS rubber shows a relatively good stability up to $190^{\circ} \mathrm{C}(0.5 \%$ mass loss being caused by the elimination of traces of solvent - endothermic effect with a minimum of $75.4^{\circ} \mathrm{C}$ ). In the interval $190-250^{\circ} \mathrm{C}$ there is a mass loss of $2.44 \%$, accompanied by an exothermic effect with a maximum of $217.6^{\circ} \mathrm{C}$, which indicates an oxidation phenomenon. The main stage of mass loss (78.89\%) takes place in the range of $250-490^{\circ} \mathrm{C}$ and is accompanied in the first part by an exothermic effect with a maximum of $359^{\circ} \mathrm{C}$, then by an endothermic effect generated by breaking some bonds and eliminating fragments such as $\mathrm{C} 11 \mathrm{H} 12$ (1-cyclopentene-1-1yl-benzene). In the range 490$635^{\circ} \mathrm{C}$ there is a mass loss of $3.85 \%$, the process being accompanied by two separate effects with maximums at 494.9 and $611.7^{\circ} \mathrm{C}$ (both exothermic effects are wide and asymmetric indicating several overlapping reactions). In principle, in this interval the residual carbon mass is oxidized. The last stage, between $635-820^{\circ} \mathrm{C}$ represents an endothermic decomposition process (mass loss is $5.56 \%$ and the minimum effect is at $781.1^{\circ} \mathrm{C}$ ). The residual mass is $8.75 \%$ and can most likely be associated with the filler used in SBS stabilization.

Sample 14 is relatively stable up to $190^{\circ} \mathrm{C}(0.57 \%$ mass loss being caused by the elimination of traces of solvent - endothermic effect with a minimum of $68.9^{\circ} \mathrm{C}$ ). In the interval $190-250^{\circ} \mathrm{C}$ there is a mass loss of $2.13 \%$, accompanied by an exothermic effect with a maximum of $231.5^{\circ} \mathrm{C}$, which indicates an oxidation phenomenon. This process takes place at a slightly higher temperature than in the control SBS sample, indicating that the incorporation of dolomite has a protective role against this oxidation process. The main stage of weight loss $(42.19 \%)$ takes place in the range of $250-470^{\circ} \mathrm{C}$ and is accompanied by two exothermic effects, partially overlapping with maximums at $363^{\circ} \mathrm{C}$ 
and $430.5^{\circ} \mathrm{C}$. Basically, the addition of dolomite delays the first oxidation process and modifies the decomposition mechanism, intervening in this interval a second oxidation process. In the range $470-625^{\circ} \mathrm{C}$ there is a mass loss of $6.35 \%$, the process being accompanied by two separate effects with maximums at 520.6 and $594.4^{\circ} \mathrm{C}$ (both exothermic effects are wide and asymmetric indicating several overlapping reactions). In principle, in this interval the residual carbon mass is oxidized. Although we have less organic matter, we have more residual carbon mass burned during this time. A possible explanation is given by the fact that in the previous stage, instead of the elimination of some large organic molecules, only a partial oxidation took place. The last stage, between $625-860^{\circ} \mathrm{C}$, represents an endothermic decomposition process (mass loss is $20.71 \%$ and the minimum effect is at 805.2 and $826.4{ }^{\circ} \mathrm{C}$ plus a shoulder at a lower temperature). The endothermic effect is clearly formed by the superposition of at least 3 individual endothermic effects. The lower temperature shoulder is also associated with the existing filler in SBS. The other two effects are specific to dolomite. It is normal for the mass loss at this stage to be higher, because in addition to the decomposition that was present in SBS, we also have the decomposition of dolomite in the sample. The residual mass is $28.06 \%$, white-gray, consisting mainly of metal oxides. Considering approximately $8 \%$ the residual mass related to SBS and based on the thermal analysis of dolomite (Sönmez et al., 2020), it can be estimated that the mass of the reinforcing agent is $\sim 40 \%$ which is in accordance with the proposed working method.

\section{Physical-Mechanical Characterisation}

Table 2 shows the physical-mechanical values obtained for SBS-based composites reinforced with kaolin and/or various amounts of dolomite. In the case of mixtures containing kaolin and modified/unmodified dolomite (samples 11-13) respectively modified dolomite powder (samples 14-15) tensile strength, presents values with 130 , 141, 212, 182 and 94\% higher compared to the control sample - SBS. A similar trend was observed in the case of the module at $300 \%$, elongations at break and tear strength, these being clearly higher compared to the control test - SBS. This clearly demonstrates that the modification of the surface of kaolin and/or dolomite with $\mathrm{SiO}_{2}$ and $\mathrm{TiO}_{2}$ precursors contributes to the reduction of the surface energy between phases, which leads to a good compatibility and implicitly to improved mechanical properties.

Table 2. Values of physical-mechanical characteristics of SBS and composites

\begin{tabular}{lcccccc}
\hline Symbol /Property & SBS & 11 & 12 & 13 & 14 & 15 \\
\hline Hardness, ${ }^{\circ}$ ShA & $60 \pm 0.05$ & $80 \pm 0.05$ & $85 \pm 0.1$ & $89 \pm 1$ & $91 \pm 0$ & $96 \pm 2.1$ \\
Tensile strength, & $1.29 \pm 0.13$ & $2.97 \pm 0.26$ & $3.11 \pm 0.07$ & $4.03 \pm 0.08$ & $3.64 \pm 0.07$ & $2.5 \pm 0.13$ \\
N/mm & & & & & & \\
Modulus at 300\% & - & $2.87 \pm 0$ & $2.89 \pm 0.04$ & $4.03 \pm 0.08$ & - & $2.23 \pm 0.3$ \\
Elongation at & $120 \pm 57.73$ & $320 \pm 34.64$ & $340 \pm 20$ & $300 \pm 0$ & $300 \pm 0$ & $360 \pm 3$ \\
break, \% & & & & & & \\
Tear strength, & $8.97 \pm 1.84$ & $17.11 \pm 0.71$ & $17.79 \pm 0.17$ & $21.52 \pm 1.15$ & $23 \pm 0.01$ & $16 \pm 0.19$ \\
N/mm & & & & & & \\
\hline
\end{tabular}

These improved mechanical properties are maintained even at high amounts of dolomite, compared to the data presented in the literature, where even the addition of $5 \%$ dolomite in PC/ABS reduces tensile strength and elongation at break, and the amounts between $10-15 \%$ almost completely compromise the properties due to the high susceptibility of dolomite to the phenomenon of agglomeration and void formation 
(Ezenkwa et al., 2019). Similar observations of diminishing elongation at break were also reported in the case of $\mathrm{SBS} /$ nanoCaCO 3 composites (at a loading degree of only 1-3 phr), attributed to the restriction of polymer chain mobility (Vahidi and Azizi, 2017).

\section{CONCLUSIONS}

Composite materials based on SBS and modified or unmodified kaolin and/or dolomite were obtained. According to the mechanical properties, it can be concluded that surface modification of the fillers can bring important improvements especially for tensile and tear strength. Furthermore, the presence of the filler leads to important thermal stabilization. These composites can be used for various applications, such as, for instance, soles for firefighters' footwear.

\section{Acknowledgements}

This work was supported by: 1. Ctr. No. 183 CI/2018 - Thermoplastic polymer and nano/micro particle-based fireproof protection sole for firefighters, and 2. Contract no. 6PFE/2018, Acronym: PERFORM-TEX-PEL.

\section{REFERENCES}

Abdelsalam, A.A., Araby, S., El-Sabbagh, S.H., Abdelmoneim, A. and Hassan, M.A. (2019), "Effect of carbon black loading on mechanical and rheological properties of natural rubber/styrene-butadiene rubber/nitrile butadiene rubber blends", Journal of Thermoplastic Composite Materials, 20(10), 1-18, https://doi.org/10.1177/0892705719844556.

Bicy, K., Abraham, J, Maria, J.H., J. and Sabu, T. (2018), "Styrene-butadiene copolymers", Encyclopedia of Polymer Science and Technology, 1-23, https://doi.org/10.1002/0471440264.pst353.pub2.

Costa, P., Silvia, C., Viana, J.C. and Lanceros Mendez, S. (2014), "Extruded thermoplastic elastomers styrenebutadiene-styrene/carbon nanotubes composites for strain sensor applications", Composites: Part B, 57, 242-24, https://doi.org/10.1016/j.compositesb.2013.10.006.

Das, C., Bansod, N.D., Kapgate, B.P., Rajkumar, K. and Das, A. (2019), "Incorporation of titania nanoparticles in elastomer matrix to develop highly reinforced multifunctional solution styrene butadiene rubber composites", Polymer, 162, 1-10, https://doi.org/10.1016/j.polymer.2018.12.022.

Ezenkwa, O.E., Ismail, A.S., Saidi, A.A.M., Rashid, A.R., Hassan, A. and Arjmandi, R. (2019), "Mechanical and thermal properties of dolomite filled polycarbonate/acrylonitrile butadiene styrene composites", PERINTIS eJournal, 9(1), 1-14.

Jin, J., Gao, Y., Wu, Y., Liu, S., Liu, R., Wei, H., Qian, G. and Zheng, J. (2021), "Rheological and adhesion properties of nano-organic palygorskite and linear SBS on the composite modified asphalt", Powder Technology, 377, 212-221, https://doi.org/10.1016/j.powtec.2020.08.080.

Perov, N.S. (2018), "Relaxation properties of thermoplastic styrene-butadiene block copolymer with nanodiamond filler", Inorganic Materials: Applied Research, 9(4), 670-674, https://doi.org/10.1134/S2075113318040275.

Sönmez, M., Alexandrescu, L., Georgescu, M., Gurau, D., Chelaru, C., Juganaru, M., Ficai, A. and Trusca, R. (2019), "Influence of adding functionalized microparticles on the physical-mechanical, structural, and processability properties of thermoplastic rubber", Leather and Footwear Journal, 19(1), 29-40, https://doi.org/10.24264/1fj.19.1.4.

Sönmez, M., Juganaru, M., Ficai, A., Ficai, D., Oprea, O., Gurau, D., Alexandrescu, L., Stelescu, M.D., Georgescu, M, Nituica, M., Melinescu, A. and Marin, M. (2020), "Dolomite surface modification with titania and silica precursors and its morphostructural and thermal characterization", Proceedings of the $8^{\text {th }}$ International Conference on Advanced Materials and Systems, 1-3 October, Bucharest, Romania, ISSN 2068-0783.

Vahidi, M. and Azizi, H. (2017), "Preparation and properties of styrene butadiene styrene/nano calcium carbonate thermoplastics elastomer composite foams: Morphology and mechanical properties", Cellular Polymers, 36(5), 251-268, https://doi.org/10.1177/026248931703600502. 